九州大学学術情報リポジトリ

Kyushu University Institutional Repository

\title{
Association of Kidney Function With Coronary Atherosclerosis and Calcification in Autopsy Samples From Japanese Elders : The Hisayama Study
}

Nakano, Toshiaki

Pathophysiological and Experimental Pathology, Department of Pathology, Graduate School of Medical Sciences, Kyushu University | Department of Medicine and Clinical Science, Graduate School of Medical Sciences, Kyushu University

Ninomiya, Toshiharu

Department of Environmental Medicine, Graduate School of Medical Sciences, Kyushu University

Sumiyoshi, Shinji

Pathophysiological and Experimental Pathology, Department of Pathology, Graduate School of Medical Sciences, Kyushu University

Fujii, Hiroshi

Pathophysiological and Experimental Pathology, Department of Pathology, Graduate School of Medical Sciences, Kyushu University

他

http://hdl. handle. net/2324/26613

出版情報: American Journal of Kidney Diseases. 55 (1)，pp.21-30，2010-01-01. Elsevier バージョン :

権利関係: (C) 2009 National Kidney Foundation, Inc. Published by Elsevier Inc. 


\section{Association of kidney function with coronary atherosclerosis and calcification in autopsy samples from Japanese elders: the Hisayama Study}

Toshiaki Nakano, $\mathrm{MD}, \mathrm{PhD}^{1,3}$, Toshiharu Ninomiya, $\mathrm{MD}, \mathrm{PhD}^{2}$, Shinji Sumiyoshi, MD, $\mathrm{PhD}^{1}$, Hiroshi Fujii, $\mathrm{MT}^{1}$, Yasufumi Doi, $\mathrm{MD}, \mathrm{PhD}^{2}$, Hideki Hirakata, $\mathrm{MD}, \mathrm{PhD}^{4}$, Kazuhiko Tsuruya, $\mathrm{MD}, \mathrm{PhD}^{3}$, Mitsuo Iida, $\mathrm{MD}, \mathrm{PhD}^{3}$, Yutaka Kiyohara, $\mathrm{MD}, \mathrm{PhD}^{2}$, Katsuo Sueishi, $\mathrm{MD}, \mathrm{PhD}^{1}$

${ }^{1}$ Pathophysiological and Experimental Pathology, Department of Pathology, ${ }^{2}$ Department of Environmental Medicine and ${ }^{3}$ Department of Medicine and Clinical Science, Graduate School of Medical Sciences, Kyushu University, Fukuoka, Japan.

${ }^{4}$ First Department of Internal Medicine, Fukuoka Red Cross Hospital, Fukuoka, Japan.

Running title: kidney function and coronary atherosclerosis

Contents:Abstract: 289 words

Text body: 2744 words (excluding title page, abstract, references, acknowledgements, tables and figures legends)

4 figures (including 2 color figures) and 3 tables

\section{Reprint requests and correspondence to:}

Toshiaki Nakano, M.D., Ph. D.

Department of Medicine and Clinical Science,

Graduate School of Medical Sciences, Kyushu University, Fukuoka, Japan.

3-1-1 Maidashi, Higashi-ku, Fukuoka 812-8582, JAPAN 
Phone: $+81-92-642-5843 \quad$ Fax: $+81-92-642-5846$

E-mail address: toshink@med.kyushu-u.ac.jp

\section{Authors' contributions}

Toshiaki Nakano contributed to the funding, planning, sampling, writing and discussion.

Toshiharu Ninomiya contributed to the planning, analysis, writing and discussion. Shinji

Sumiyoshi, Hiroshi Fuji and Yasufumi Doi contributed to the sampling and discussion.

Hideki Hirakata, Kazuhiko Tsuruya and Mitsuo Iida contributed to the writing and discussion.

Yutaka Kiyohara and Katsuo Sueishi contributed to the funding, writing and discussion. All authors have seen and approved the final version.

\section{Support and financial disclosure declaration}

This work was supported in part by a Grant-in-Aid (T. Nakano, Y. Kiyohara and K. Sueishi) from the Japanese Ministry of Education, Culture, Sports, Science, and Technology, a Grant-in-Aid for Scientific Research C (T.N., No. 20590342), A (Y.K., No. 18209024) and A (K.S., No. 19209012), a grant from the Special Coordination Fund for Promoting Science and a grant from the Technology and Innovative Development Project in Life Sciences from the Ministry of Education, Culture, Sports, Science and Technology of Japan.

Financial Disclosure: None. 


\section{Abstract}

Background: Chronic kidney disease (CKD) is associated with increased risk of coronary heart disease. However, information regarding the histopathology of coronary atherosclerosis in individuals with CKD remains scarce. This study investigated the relationship between CKD and the severity of coronary atherosclerosis in population-based autopsy samples. Study Design: Cross-sectional study.

Setting \& Participants: 126 subjects randomly selected from 844 consecutive population-based autopsy samples.

Predictor: Estimated glomerular filtration rate (eGFR), which was estimated using the simplified prediction equation derived from the Modification of Diet in Renal Disease (MDRD) Study.

Outcomes: The severity of atherosclerosis in three main coronary arteries, including atherosclerotic lesions types defined by American Heart Association (AHA) classification, stenosis rates and coronary calcified lesions.

Measurements: The relationship between CKD and the severity of coronary atherosclerosis were evaluated by using the generalized estimating equations methods.

Results: The frequencies of advanced atherosclerotic lesions increased gradually as eGFR decreased (33.6, 41.7, 52.3, and $52.8 \%$ for eGFRs of $\geq 60,45-59,30-44$ and $<30 \mathrm{ml} / \mathrm{min} / 1.73$ $\mathrm{m}^{2}$, respectively, $p$ for trend $=0.006$ ). This relationship remained substantially unchanged even after adjustment for potential confounding factors (odds ratio, 1.40 [95\% confidential interval, 0.76-2.55], 2.02 [0.99-4.15], and 3.02 [1.22-7.49] for eGFRs of 45-59, 30-44 and $<30 \mathrm{ml} / \mathrm{min} / 1.73 \mathrm{~m}^{2}$, respectively). The frequencies of calcified lesions of coronary arteries also increased gradually with lower eGFR levels ( $\mathrm{p}$ for trend $=0.02$ ). Hypertension and diabetes was associated with the increased risk of advanced coronary atherosclerosis and calcification of coronary arteries in individual with reduced eGFR. 
Limitations: Cross-sectional study, absence of data on proteinuria and the extremely high proportion of aged people.

Conclusions: The autopsy findings presented here suggest that CKD is associated significantly with the severity of coronary atherosclerosis. Patients with CKD should be considered a high-risk population for advanced coronary atherosclerosis.

Key words- Chronic kidney disease, coronary atherosclerosis, population risk, coronary artery stenosis, glomerular filtration rate, coronary disease.

\section{Abbreviations:}

AHA: American Heart Association

CKD: Chronic kidney disease

EEL: external elastic lamina

eGFR: estimated glomerular filtration rate

IEL: internal elastic lamina

MDRD: the Modification of Diet in Renal Disease 


\section{Introduction}

Chronic kidney disease (CKD) is a significant public health problem, affecting $10-15 \%$ of the adult general population in developed countries. ${ }^{1-3} \mathrm{CKD}$ is associated with an increased risk of cardiovascular disease and death. ${ }^{4-7}$ A higher incidence rate of myocardial infarction and excessive cardiac mortality has repeatedly been documented in patients with CKD ${ }^{6-10}$ Cardiac failure is more common in patients with advanced CKD, showing a prevalence of approximately $40 \% .^{11}$

Several autopsy-based studies revealed a higher prevalence of arteriosclerotic lesions in individuals with CKD than in those without it. ${ }^{12-14}$ Furthermore, patients with end-stage renal disease showed more advanced atherosclerotic lesions with calcification in coronary arteries than the general population. ${ }^{14}$ However, these studies were conducted in hospital-based populations which are prone to underlying disease. Additionally, there are few studies investigating the histopathological findings of coronary artery in individuals with moderate stage of CKD.

The Hisayama study is a prospective population-based study of cardiovascular disease risk factors in Japanese people, ${ }^{15}$ and is characterized by autopsy verification of the cause of death in approximately $80 \%$ of deceased people. ${ }^{16,17}$ The current study assessed the relationship between reduced kidney function and the severity of coronary atherosclerosis in the population-based autopsy samples. 


\section{Methods}

\section{Study population}

The Hisayama Study was established in 1961 in the town of Hisayama, a suburban community adjacent to Fukuoka City in a metropolitan area of Kyushu Island in southern Japan. The population of Hisayama is approximately 7,000 and has been stable for 40 years. Full community surveys of residents have been repeated since $1961 .{ }^{18}$ From January 1988 to November 2005, a total of 1,162 residents of Hisayama died; of these, 844 underwent autopsy examination. Subjects without health examination data within 3 years before death were excluded. The remaining 482 subjects were classified into four categories based on estimated glomerular filtration rate (eGFR): $\geq 60,45-59,30-44$, and $<30 \mathrm{ml} / \mathrm{min} / 1.73 \mathrm{~m}^{2}$ (data from the most recent health examination). Eighteen subjects had a eGFR $<30$ $\mathrm{ml} / \mathrm{min} / 1.73 \mathrm{~m}^{2}$. The subjects included in this study were randomly selected using computer-generated random number from each category of eGFR level after matching for age at death and sex at a 1:2 ratio against subjects in the $<30 \mathrm{ml} / \mathrm{min} / 1.73 \mathrm{~m}^{2}$ category. A final total of 126 subjects (49 men and 77 women) were enrolled in this study (figure 1). The median period from the last health examination to death was 1.0 years (interquartlie range [IQR] 0.0-2.0).

\section{Risk factors}

At each health examination, study participants undertook a self-administered questionnaire covering medical history, antihypertensive treatment, smoking habits, and alcohol intake. The completed questionnaire was checked by trained interviewers. Blood pressures were measured three times using a standard mercury sphygmomanometer at each examination, with mean values used for the analysis. Hypertension was defined as a systolic 
blood pressure $\geq 140 \mathrm{mmHg}$ and/or diastolic blood pressure $\geq 90 \mathrm{mmHg}$ or by the use of antihypertensive agents. Blood samples were collected after overnight fasting. Serum creatinine concentrations were measured using the Jaffé method. Hemoglobin A1c levels were measured by high-performance liquid chromatography (HPLC). Diabetes mellitus was diagnosed by a hemoglobin $A_{1 c} \geq 6.0 \%$. Total cholesterol, high-density lipoprotein (HDL) cholesterol, and triglycerides were determined enzymatically. Dyslipidemia was defined by a total cholesterol concentration $\geq 220 \mathrm{mg} / \mathrm{dL}, \mathrm{HDL}$ cholesterol $\leq 40 \mathrm{mg} / \mathrm{dL}$ or triglycerides $\geq 150 \mathrm{mg} / \mathrm{dL}$ (Total cholesterol, HDL cholesterol and triglycerides in $\mathrm{mg} / \mathrm{dL}$ may be converted to $\mathrm{mmol} / \mathrm{L}$ by multiplying by $0.02586,0.02586$ and 0.01129 , respectively).

\section{Definition of chronic kidney disease}

eGFR was estimated using the simplified prediction equation derived from the 6-variable Modification of Diet in Renal Disease (MDRD) Study ${ }^{19}$ and given by the following equation:

$$
\begin{aligned}
& \text { eGFR }\left(\mathrm{ml} / \mathrm{min} / 1.73 \mathrm{~m}^{2}\right)=170 \times[\text { serum creatinine }(\mathrm{mg} / \mathrm{dl})]^{-0.999} \\
& \times[\text { age }(\text { years })]^{-0.176} \times[\text { serum urea nitrogen }(\mathrm{mg} / \mathrm{dl})]^{-0.170} \\
& \times[\text { serum albumin }(\mathrm{g} / \mathrm{dl})]^{0.318} \times[0.762 \text { if female }]
\end{aligned}
$$

eGFR levels were classified into four categories: $\geq 60,45-59,30-44$, and $<30 \mathrm{ml} / \mathrm{min} / 1.73 \mathrm{~m}^{2}$, according to the National Kidney Foundation Kidney Disease Outcomes Quality Initiative guidelines. $^{20}$

For the sensitivity analyses, eGFR was also estimated using 4-variable MDRD equation modified with the Japanese Society of Nephrology-Chronic Kidney Disease Initiatives coefficient (JSN-CKDI equation) as below: ${ }^{21}$

$$
\text { JSN-eGFR }\left(\mathrm{ml} / \mathrm{min} / 1.73 \mathrm{~m}^{2}\right)=0.808 \times 175
$$


$\mathrm{x}$ [serum creatinine (enzymatic method $[\mathrm{mg} / \mathrm{dL}])]^{-1.154}$

$\mathrm{x}$ [age (years) $]^{-0.203} \mathrm{x}[0.742$ if female $]$,

where the value of serum creatinine measured by Jaffe methods was converted to the values for the enzymatic method by subtracting $0.207 \mathrm{mg} / \mathrm{dl} .^{22}$

\section{Coronary artery morphology}

Heart tissue obtained at autopsy was immersed in $10 \%$ buffered formaldehyde for at least 24 hours, making sure to include the three main coronary arteries. The right coronary artery (segment 1), left anterior descending coronary artery (segment 6), and left circumflex coronary artery (segment 11) were dissected free from the surface of the heart, cut perpendicular to the long axis at 3-mm intervals, and then embedded in paraffin. The segment of the vessel showing the most severe stenosis was selected for histological examination, excluding areas near the branching site. We excluded 3 blocks missing to define the segments of coronary arteries. Finally, 375 blocks were obtained and all the blocks for each subject cut into $3-\mu \mathrm{m}$-thick serial sections in one sequence $(1$ block provided insufficient sample to estimate the extent of arterial stenosis). Sections from each block were serially subjected to hematoxylin and eosin (H.E.), elastica-van Gieson's, and Masson's trichrome stainings. The histological examinations were made without reference to the associated clinical information by two independent pathologists (T. Nakano and S. Sumiyoshi) (blinded assessments).

\section{Estimation of atherosclerotic lesions}

Atherosclerotic lesions found in each section were classified into six types in accordance with the definitions proposed by the Committee on Vascular Lesions of the Council on Atherosclerosis, $\mathrm{AHA}^{23}$ : Type I (initial lesion), intimal thickening with isolated foam cells; Type II (fatty-streak lesion), intimal thickening with intracellular lipid 
accumulation; Type III (intermediate lesion), type II changes and small extracellular lipid pools; Type IV (atheroma), type II changes and core of extracellular lipid; Type V (fibroatheroma), lipid core and fibrotic layer to lesions, or mainly calcified, or mainly fibrotic; Type VI (complicated lesion), disrupted lesion with hematoma or hemorrhage or thrombotic deposits. The AHA classification defines advanced atherosclerotic lesions as types IV through VI. ${ }^{23}$ Lesion calcification was assessed on H.E.-stained paraffin sections from all specimens.

\section{Morphometry of luminal stenosis in the coronary artery}

All arteries were analyzed quantitatively for stenosis rate by computerized planimetry according to Taylor et al. ${ }^{24}$ Morphometry was performed using NIH Image software (version 1.63, National Institutes of Health, MD). Elastica-van Gieson's-stained sections were magnified and digitized to measure the luminal, internal elastic lamina (IEL), and external elastic lamina (EEL) perimeters. Arterial areas were calculated from the diameter values derived from the measured arterial perimeter $\left(\operatorname{are} a=\pi r^{2}\right)$ to avoid artifacts from vessel shape distortion during processing. Plaque areas were calculated as the differences between IEL and luminal area measurements. Percentage luminal stenosis was calculated as the plaque area/IEL area $\times 100 .^{24}$

\section{Statistical analysis}

The SAS software package for Windows, version 9.1 (SAS Institute, Inc, Cary, NC) was used to perform statistical analyses. Trends in the mean values or frequencies of variables across the subgroups of eGFR level were tested by using linear regression analysis or logistic regression analysis, respectively. The mean values of stenosis rate according to eGFR levels were calculated by using linear mixed model to account for the correlation 
between vessels within a patient. The stenosis rates between vessels were fairly correlated with the correlation coefficient ranged from 0.21 to 0.32 . This analysis was carried out using the procedure "MIXED" in SAS. The odds ratios (ORs) and their 95\% confidence intervals (CIs) were estimated using the generalized estimating equations methods to deal with modeling the correlation among repeated outcomes within a patient. ${ }^{25}$ The correlation coefficients for the probabilities of advanced atherosclerosis and calcified lesion between vessels ranged from 0.08 to 0.34 and from 0.25 to 0.37 , respectively. These analyses were performed using procedure "GENMOD" in SAS. Trends in relationships between eGFR levels and the risk of outcomes were tested by adding the median value of eGFR for each category to the relevant model. A two-tailed $\mathrm{p}<0.05$ was defined as statistically significant.

\section{Results}

\section{Baseline characteristics}

Table 1 details the baseline clinical and demographic characteristics of the study subjects according to eGFR levels. Subjects with lower eGFR levels had higher systolic blood pressure and calcium-phosphorus product, and lower hematocrit. The frequency of hypertension, usage of anti-hypertensive agents increased significantly with decreased eGFR levels. The mean values or frequencies of other potential risk factors were not statistically different among the eGFR levels.

\section{Relationship between kidney function and severity of atherosclerotic lesions}

Figure 2 represents a typical coronary artery for subgroups of eGFR levels. The ageand sex-adjusted mean values of coronary artery stenosis rate increased significantly with lower eGFR levels (mean \pm SE: $46.7 \pm 1.9,49.2 \pm 1.9,51.9 \pm 1.9$, and $53.7 \pm 2.7 \%$ for eGFRs of $\geq 60,45-59,30-44$ and $<30 \mathrm{ml} / \mathrm{min} / 1.73 \mathrm{~m}^{2}$, respectively, $p$ for trend $=0.02$ ). 
Figure 3 shows the proportions of the atherosclerotic lesion in accordance with the AHA classification according to eGFRs. The prevalence of advanced atherosclerotic lesions defined as type IV through VI was $34.3 \%$ for eGFRs $\geq 60 \mathrm{ml} / \mathrm{min} / 1.73 \mathrm{~m}^{2}, 41.7 \%$ for eGFRs $45-59 \mathrm{ml} / \mathrm{min} / 1.73 \mathrm{~m}^{2}, 52.3 \%$ for eGFRs $30-44 \mathrm{ml} / \mathrm{min} / 1.73 \mathrm{~m}^{2}$, and $52.8 \%$ for eGFRs $<30$ $\mathrm{ml} / \mathrm{min} / 1.73 \mathrm{~m}^{2}$. Subjects in the latter two categories had a significantly higher proportion of advanced atherosclerotic lesions on autopsy than those with eGFRs of $\geq 60 \mathrm{ml} / \mathrm{min} / 1.73 \mathrm{~m}^{2}$. The risk of advanced atherosclerosis was doubled in subjects with eGFRs of $<45 \mathrm{ml} / \mathrm{min} / 1.73$ $\mathrm{m}^{2}$ as compared to those with eGFR of $\geq 60 \mathrm{ml} / \mathrm{min} / 1.73 \mathrm{~m}^{2}$ after adjustment for the potential confounding factors including age, sex, hypertension, diabetes, total cholesterol, HDL-cholesterol, triglycerides, calcium-phosphorus product, hematocrit, smoking habits and alcohol intake (Table 2).

\section{Prevalence of calcified lesion in coronary artery according to kidney function}

In a case of AHA type VI in the subgroup of eGFRs $<30 \mathrm{ml} / \mathrm{min} / 1.73 \mathrm{~m}^{2}$, the arterial intima was thickened and associated with calcified plaque and hematoma (Figure 4). Many coronary artery samples showed intimal calcified lesions, but there was no medial calcification in any specimens examined here. The prevalence of calcified lesions was $36.5 \%$ for eGFRs $\geq 60 \mathrm{ml} / \mathrm{min} / 1.73 \mathrm{~m}^{2}, 37.0 \%$ for eGFRs of $45-59 \mathrm{ml} / \mathrm{min} / 1.73 \mathrm{~m}^{2}, 44.9 \%$ for eGFRs of $30-44 \mathrm{ml} / \mathrm{min} / 1.73 \mathrm{~m}^{2}$, and $60.4 \%$ for eGFRs $<30 \mathrm{ml} / \mathrm{min} / 1.73 \mathrm{~m}^{2}$ (p for trend $=0.02$ ). Lower eGFR was associated with a higher prevalence of calcified coronary artery lesions. The multivariate-adjusted OR of calcified lesions was 4.71 (95\% CI 1.78 - 12.50) in subjects with GFRs $<30 \mathrm{ml} / \mathrm{min} / 1.73 \mathrm{~m}^{2}$ as compared to those with GFRs $>60 \mathrm{ml} / \mathrm{min} / 1.73$ $\mathrm{m}^{2}$ (Table 2). 
Association of cardiovascular risk factors with the risk of the advanced atherosclerotic lesion and calcified lesion in subjects with reduced eGFR

Next, we assessed the relationship between the prevalence of advanced atherosclerotic lesions and cardiovascular risk factors such as hypertension, diabetes, and dyslipidemia in subjects with eGFR below $60 \mathrm{ml} / \mathrm{min} / 1.73 \mathrm{~m}^{2}$ (Table 3). The risk of advanced atherosclerotic lesions tended toward higher in subjects with hypertension than those without hypertension (OR 1.76, $95 \%$ CI $0.93-3.35$ ). Subjects with diabetes had significantly higher risk of advanced atherosclerotic lesions (OR 2.57, 95\% CI 1.26 - 5.24). Likewise, hypertension and diabetes was associated significantly with the increased risk of calcified lesion in subjects with eGFR below $60 \mathrm{ml} / \mathrm{min} / 1.73 \mathrm{~m}^{2}$ (OR 1.88, $95 \%$ CI 1.04 - 3.39 for hypertension; OR $2.91,95 \%$ CI $1.56-5.45$ for diabetes).

\section{Sensitivity analyses using JSN-CKDI equation to estimate eGFR levels}

We also estimated eGFR values with JSN-CKDI equation ${ }^{21}$. the distribution of JSN-eGFR (median 49, IQR 35-65) was almost comparable with that of eGFR estimated with MDRD equation (median 52, IQR 39-64) and these values were well-correlated ( $\mathrm{r}=0.98$, $\mathrm{p}<0.0001)$. The median values of JSN-eGFR for each category of eGFR estimated with MDRD equation was 77 (IQR 71-83), 54 (48-56), 36 (33-39) and $18(15-21) \mathrm{ml} / \mathrm{min} / 1.73 \mathrm{~m}^{2}$ for eGFR categories of $\geq 60,45-59,30-44$ and $<30 \mathrm{ml} / \mathrm{min} / 1.73 \mathrm{~m}^{2}$, respectively. The sensitivity analyses using JSN-CKDI equation to estimate eGFR levels made a little difference in the findings. The age- and sex-adjusted mean values of coronary artery stenosis rate increased gradually with lower JSN-eGFR levels (mean \pm SE: 47.3 $\pm 1.9,49.4 \pm 2.1$, $51.7 \pm 2.0$, and $52.3 \pm 2.6 \%$ for eGFRs-JSN of $\geq 60,45-59,30-44$ and $<30 \mathrm{ml} / \mathrm{min} / 1.73 \mathrm{~m}^{2}$, respectively, $p$ for trend $=0.06$ ). Lower JSN-eGFR levels were associated significantly with 
higher risks of advanced atherosclerosis and calcified lesion after adjusting for age and sex (both $\mathrm{p}$ for trend $=0.04$ ). Subjects with JSN-eGFR of $<30 \mathrm{ml} / \mathrm{min} / 1.73 \mathrm{~m}^{2}$ were likely to have greater risks of advanced atherosclerosis (OR 1.80, 95\% CI 0.70-4.64) and calcified lesion (OR 3.90, 95\% CI 1.45-10.49) than subjects with JSN-eGFR of $\geq 60 \mathrm{ml} / \mathrm{min} / 1.73 \mathrm{~m}^{2}$ after adjusting for above-mentioned confounding factors.

\section{Discussion}

This study demonstrated a clear relationship between lower kidney function and the severity of coronary atherosclerosis in autopsy samples from a general population. To the best of our knowledge, this is the first histopathological study showing the gradual progression of coronary atherosclerosis even in individuals with moderate CKD. Additionally, cardiovascular risk factor including hypertension, diabetes and dyslipidemia was associated with higher risk of advanced coronary atherosclerosis and calcified lesion in individuals with CKD. These findings imply the importance of the management of cardiovascular risk factors before reaching advanced stage of CKD in order to reduce the risk of coronary atherosclerosis.

Several authors have reported the relationship between kidney function and coronary atherosclerosis in people with advanced kidney failure. Lindner et al. showed that approximately $35 \%$ of all deaths in patients receiving hemodialysis were caused by coronary heart disease, partly confirmed by autopsy. ${ }^{26}$ Cross-sectional studies also demonstrated that more than half of predialytic patients without any sign and history of angina or myocardial infarction have had a significant coronary artery stenosis, proven by coronary angiography. ${ }^{27}$, ${ }^{28}$ Additionally, uremic patients are more likely to have coronary atherosclerotic lesions with plaque, medial thickness, and calcification than nonuremic patients in an autopsy-based study. ${ }^{14}$ In the present study, the prevalence of advanced coronary atherosclerotic lesions 
increased gradually even in individuals with moderate stage of CKD. These results thus highlighted the importance of considering kidney function status, prior to the patient reaching advanced CKD, in trying to reduce the burden of coronary atherosclerosis in the general population.

Several potential mechanisms can explain the association demonstrated here. Individuals with CKD often have a higher burden of traditional cardiovascular risk factors such as aging, elevated blood pressure, diabetes, dyslipidemia. ${ }^{29}$ Additionally, a reduced eGFR may be associated with increased levels of novel cardiovascular disease risk factors, such as inflammation, oxidative stress, anemia, and abnormal calcium/phosphate metabolism. ${ }^{29-31}$ Several experimental findings from uremic Apolipoprotein E knockout mice support these results. ${ }^{32-35}$ In the present study, the significant association between reduced GFR and severity of coronary arteriosclerosis was still observed even after adjustment for all the major traditional cardiovascular risk factors and some of the novel factors, including anemia and abnormal calcium/phosphate metabolism. However, we were unable to sufficiently assess how these other potential confounding factors influenced the study findings. Further exploration is clearly needed to map the risk factors for coronary atherosclerosis in individuals with CKD.

Several limitations of our study should be discussed. First, this was a cross-sectional study, and so difficult to infer causality between CKD and risk for progression of coronary atherosclerosis. The findings, however, suggested strongly that individuals with CKD should be examined for progressive coronary atherosclerosis. Second, it has been well recognized that GFR estimated using the MDRD equation leads to a certain degree of misclassification of eGFR levels. However this limitation is unlikely to change our conclusions, because the sensitivity analysis using the JSN-CKDI equation to estimate eGFR did not make any material differences in the findings. Third, there was no information available regarding the 
severity or duration of hypertension and other cardiovascular disease risk factors. Furthermore, we have also no data available on medication usage such as lipid lowering agents and phosphate binders. This limitation may reduce the experimental accuracy to some extent. Finally, this study is based on autopsy and the proportion of aged people is extremely high. Thus, these findings might not be applicable to the general living population. Nevertheless, the information gained in this study contributes meaningfully towards better understanding the pathogenesis of coronary atherosclerosis in individuals with CKD.

In conclusion, reduced eGFR was associated significantly with severity of coronary atherosclerosis. The findings emphasized that individuals with CKD should be considered a high-risk population for coronary heart disease, and that cardiovascular risk factors should be substantially monitored in this population to prevent the progression of coronary atherosclerosis. Further studies are needed to elucidate the precise mechanism mediating the deterioration of atherosclerotic lesions in individuals with CKD.

\section{Acknowledgments}

The authors thank the residents of Hisayama Town for their participation in the survey and the staff of the Division of Health and Welfare of Hisayama for their cooperation in this study.

This work was supported in part by a Grant-in-Aid (T. Nakano, Y. Kiyohara and K. Sueishi) from the Japanese Ministry of Education, Culture, Sports, Science, and Technology, a Grant-in-Aid for Scientific Research C (T.N., No. 20590342), A (Y.K., No. 18209024) and A (K.S., No. 19209012), a grant from the Special Coordination Fund for Promoting Science and a grant from the Technology and Innovative Development Project in Life Sciences from the Ministry of Education, Culture, Sports, Science and Technology of Japan.

Financial Disclosure: None. 


\section{References}

1. Coresh J, Astor BC, Greene T, Eknoyan G, Levey AS. Prevalence of chronic kidney disease and decreased kidney function in the adult US population: Third National Health and Nutrition Examination Survey. Am J Kidney Dis. 2003;41(1):1-12.

2. Chadban SJ, Briganti EM, Kerr PG, et al. Prevalence of kidney damage in Australian adults: The AusDiab kidney study. J Am Soc Nephrol. 2003;14(7 Suppl 2):S131-138.

3. Irie $\mathrm{F}$, Iso $\mathrm{H}$, Sairenchi $\mathrm{T}$, et al. The relationships of proteinuria, serum creatinine, glomerular filtration rate with cardiovascular disease mortality in Japanese general population. Kidney Int. 2006;69(7):1264-1271.

4. Go AS, Chertow GM, Fan D, McCulloch CE, Hsu CY. Chronic kidney disease and the risks of death, cardiovascular events, and hospitalization. $N$ Engl J Med. 2004;351(13):1296-1305.

5. Manjunath $\mathrm{G}$, Tighiouart $\mathrm{H}$, Ibrahim $\mathrm{H}$, et al. Level of kidney function as a risk factor for atherosclerotic cardiovascular outcomes in the community. J Am Coll Cardiol. 2003;41(1):47-55.

6. Muntner P, He J, Hamm L, Loria C, Whelton PK. Renal insufficiency and subsequent death resulting from cardiovascular disease in the United States. J Am Soc Nephrol. 2002;13(3):745-753.

7. Ninomiya T, Kiyohara Y, Kubo M, et al. Chronic kidney disease and cardiovascular disease in a general Japanese population: the Hisayama Study. Kidney Int. 2005;68(1):228-236.

8. Rubenstein MH, Harrell LC, Sheynberg BV, Schunkert H, Bazari H, Palacios IF. Are patients with renal failure good candidates for percutaneous coronary revascularization in the new device era? Circulation. 2000;102(24):2966-2972. 
9. Beddhu S, Allen-Brady K, Cheung AK, et al. Impact of renal failure on the risk of myocardial infarction and death. Kidney Int. 2002;62(5):1776-1783.

10. Fried LF, Shlipak MG, Crump C, et al. Renal insufficiency as a predictor of cardiovascular outcomes and mortality in elderly individuals. J Am Coll Cardiol. 2003;41(8):1364-1372.

11. Foley RN, Parfrey PS, Sarnak MJ. Clinical epidemiology of cardiovascular disease in chronic renal disease. Am J Kidney Dis. 1998;32(5 Suppl 3):S112-119.

12. Ansari A, Kaupke CJ, Vaziri ND, Miller R, Barbari A. Cardiac pathology in patients with end-stage renal disease maintained on hemodialysis. Int J Artif Organs. $1993 ; 16(1): 31-36$.

13. Clyne N, Lins LE, Pehrsson SK. Occurrence and significance of heart disease in uraemia. An autopsy study. Scand J Urol Nephrol. 1986;20(4):307-311.

14. Schwarz U, Buzello M, Ritz E, et al. Morphology of coronary atherosclerotic lesions in patients with end-stage renal failure. Nephrol Dial Transplant. 2000;15(2):218-223.

15. Katsuki S. Epidemiological and clinicopathological study on cerebrovascular disease in Japan. Prog Brain Res. 1966;21:64-89.

16. Ohmura T, Ueda K, Kiyohara Y, et al. Prevalence of type 2 (non-insulin-dependent) diabetes mellitus and impaired glucose tolerance in the Japanese general population: the Hisayama Study. Diabetologia. 1993;36(11):1198-1203.

17. Kubo M, Kiyohara Y, Kato I, et al. Risk factors for renal glomerular and vascular changes in an autopsy-based population survey: the Hisayama study. Kidney Int. 2003;63(4):1508-1515.

18. Ueda K, Omae T, Hirota Y, Takeshita M, Hiyoshi Y. Epidemiological and clinco-pathological study on renal diseases observed in the autopsy cases in Hisayama population, Kyushu Island, Japan. J Chronic Dis. 1976;29(3):159-173. 
19. Levey AS, Bosch JP, Lewis JB, Greene T, Rogers N, Roth D. A more accurate method to estimate glomerular filtration rate from serum creatinine: a new prediction equation. Modification of Diet in Renal Disease Study Group. Ann Intern Med. 1999;130(6):461-470.

20. K/DOQI clinical practice guidelines for chronic kidney disease: evaluation, classification, and stratification. Am J Kidney Dis. 2002;39(2 Suppl 1):S1-266.

21. Matsuo S, Imai E, Horio M, et al. Revised Equations for Estimated GFR From Serum Creatinine in Japan. Am J Kidney Dis. 2009 (in press).

22. Imai E, Horio M, Nitta K, et al. Estimation of glomerular filtration rate by the MDRD study equation modified for Japanese patients with chronic kidney disease. Clin Exp Nephrol. 2007;11(1):41-50.

23. Stary HC, Chandler AB, Dinsmore RE, et al. A definition of advanced types of atherosclerotic lesions and a histological classification of atherosclerosis. A report from the Committee on Vascular Lesions of the Council on Arteriosclerosis, American Heart Association. Circulation. 1995;92(5):1355-1374.

24. Taylor AJ, Burke AP, Farb A, et al. Arterial remodeling in the left coronary system: the role of high-density lipoprotein cholesterol. J Am Coll Cardiol. 1999;34(3):760-767.

25. Zeger SL, Liang KY. Longitudinal data analysis for discrete and continuous outcomes. Biometrics. 1986;42(1):121-130.

26. Lindner A, Charra B, Sherrard DJ, Scribner BH. Accelerated atherosclerosis in prolonged maintenance hemodialysis. N Engl J Med. 1974;290(13):697-701.

27. Joki N, Hase H, Nakamura R, Yamaguchi T. Onset of coronary artery disease prior to initiation of haemodialysis in patients with end-stage renal disease. Nephrol Dial Transplant. 1997;12(4):718-723.

28. Ohtake T, Kobayashi S, Moriya H, et al. High prevalence of occult coronary artery 
stenosis in patients with chronic kidney disease at the initiation of renal replacement therapy: an angiographic examination. J Am Soc Nephrol. 2005;16(4):1141-1148.

29. Uhlig K, Levey AS, Sarnak MJ. Traditional cardiac risk factors in individuals with chronic kidney disease. Semin Dial. 2003;16(2):118-127.

30. Madore F. Uremia-related metabolic cardiac risk factors in chronic kidney disease. Semin Dial. 2003;16(2):148-156.

31. Witko-Sarsat V, Friedlander M, Nguyen Khoa T, et al. Advanced oxidation protein products as novel mediators of inflammation and monocyte activation in chronic renal failure. J Immunol. 1998;161(5):2524-2532.

32. Buzello M, Tornig J, Faulhaber J, Ehmke H, Ritz E, Amann K. The apolipoprotein e knockout mouse: a model documenting accelerated atherogenesis in uremia. J Am Soc Nephrol. 2003;14(2):311-316.

33. Bro S, Bentzon JF, Falk E, Andersen CB, Olgaard K, Nielsen LB. Chronic renal failure accelerates atherogenesis in apolipoprotein E-deficient mice. J Am Soc Nephrol. 2003;14(10):2466-2474.

34. Bro S, Moeller F, Andersen CB, Olgaard K, Nielsen LB. Increased expression of adhesion molecules in uremic atherosclerosis in apolipoprotein-E-deficient mice. J Am Soc Nephrol. 2004;15(6):1495-1503.

35. Massy ZA, Ivanovski O, Nguyen-Khoa T, et al. Uremia accelerates both atherosclerosis and arterial calcification in apolipoprotein E knockout mice. J Am Soc Nephrol. 2005;16(1):109-116. 


\section{Figure legends}

\section{Figure 1: Flow diagram for enrollment of the study}

Figure 2: Typical arteries for each classification by glomerular filtration rate.

A through D show typical light microscopic views of coronary arteries from respective cases with eGFRs $\geq 60$ (A), 45-59 (B), 30-44 (C), and $<30 \mathrm{ml} / \mathrm{min} / 1.73 \mathrm{~m}^{2}$ (D). The stenosis rates of respective arteries were 36.8\%(A), 42.3\% (B), 54.2\%(C), and 58.9\%(D). All sections were stained with hematoxylin eosin (H.E.). Scale bars $=1.0 \mathrm{~mm}$.

Figure 3: The proportions of the atherosclerotic lesion in accordance with the AHA classification associated with kidney function.

Bar graphs indicate the percentage of atherosclerotic lesions estimated on the basis of the AHA classifications according to eGFR levels. The percentages of advanced atherosclerosis (AHA types IV to VI) for respective eGFR levels are shown at the right side of the graphs. ${ }^{*} p<0.05$ vs. eGFR of $\geq 60 \mathrm{ml} / \mathrm{min} / 1.73 \mathrm{~m}^{2}$.

Figure 4. Typical artery of AHA type VI in GFR<30 category (Masson's trichrome staining). Scale bars $=1.0 \mathrm{~mm}$. 
Table 1: Laboratory variables and risk factors according to kidney function

\begin{tabular}{|c|c|c|c|c|c|}
\hline & \multicolumn{4}{|c|}{ eGFR categories $\left(\mathrm{ml} / \mathrm{min} / 1.73 \mathrm{~m}^{2}\right)$} & \multirow{2}{*}{$\begin{array}{l}\mathrm{p} \text { for } \\
\text { trend }\end{array}$} \\
\hline & $\geq 60$ & $45-59$ & $30-44$ & $<30$ & \\
\hline eGFR $\left(\mathrm{ml} / \mathrm{min} / 1.73 \mathrm{~m}^{2}\right)$ & $72(68-85)$ & $55(51-58)$ & $40(37-43)$ & $21(19-25)$ & \\
\hline Number & 36 & 36 & 36 & 18 & \\
\hline Age & $84 \pm 6$ & $85 \pm 6$ & $85 \pm 8$ & $85 \pm 7$ & 0.8 \\
\hline Male $(\%)$ & 39 & 39 & 39 & 39 & 0.9 \\
\hline Serum creatinine $(\mathrm{mg} / \mathrm{dL})$ & $0.9(0.8-1.0)$ & $1.1(1.0-1.3)$ & $1.5(1.3-1.7)$ & $2.5(2.0-3.2)$ & $<0.001$ \\
\hline Serum urea nitrogen $(\mathrm{mg} / \mathrm{dL})$ & $16(12-18)$ & $19(16-24)$ & $24(19-27)$ & $39(29-46)$ & $<0.001$ \\
\hline Serum albumin $(\mathrm{g} / \mathrm{dL})$ & $4.0 \pm 0.4$ & $4.0 \pm 0.5$ & $3.9 \pm 0.5$ & $3.7 \pm 0.4$ & 0.11 \\
\hline Systolic blood pressure (mmHg) & $141 \pm 23$ & $142 \pm 29$ & $143 \pm 29$ & $165 \pm 29$ & 0.01 \\
\hline Diastolic blood pressure $(\mathrm{mmHg})$ & $73 \pm 12$ & $74 \pm 14$ & $75 \pm 10$ & $77 \pm 13$ & 0.2 \\
\hline Usage of anti-hypertensive agent (\%) & 28 & 36 & 56 & 50 & 0.03 \\
\hline Hypertension $(\%)$ & 61 & 58 & 78 & 94 & 0.006 \\
\hline Hemoglobin $A_{1 c}(\%)$ & $5.2 \pm 0.8$ & $5.7 \pm 1.5$ & $5.4 \pm 0.8$ & $5.4 \pm 0.9$ & 0.6 \\
\hline Diabetes $(\%)$ & 11 & 22 & 19 & 22 & 0.3 \\
\hline Total cholesterol (mg/dL) & $184 \pm 37$ & $190 \pm 43$ & $195 \pm 53$ & $186 \pm 45$ & 0.6 \\
\hline $\mathrm{HDL}-\mathrm{C}(\mathrm{mg} / \mathrm{dL})$ & $60 \pm 17$ & $52 \pm 13$ & $56 \pm 17$ & $53 \pm 15$ & 0.3 \\
\hline Triglycerides (mg/dL) & $76(65-102)$ & $91(81-124)$ & $88(68-123)$ & $113(70-167)$ & 0.1 \\
\hline Calcium $\times$ Phosphate $\left(\mathrm{mg}^{2} / \mathrm{dL}^{2}\right)$ & $29 \pm 6$ & $31 \pm 5$ & $31 \pm 4$ & $33 \pm 5$ & 0.005 \\
\hline Hematocrit $(\%)$ & $37 \pm 5$ & $37 \pm 6$ & $35 \pm 5$ & $30 \pm 6$ & $<0.001$ \\
\hline Smoking habits $(\%)$ & 19 & 28 & 6 & 17 & 0.3 \\
\hline Alcoholic intake $(\%)$ & 17 & 11 & 11 & 6 & 0.3 \\
\hline $\begin{array}{l}\text { The median period from the last health } \\
\text { examination }\end{array}$ & $1.0(0.5-2.0)$ & $2.0(0.5-2.0)$ & $1.5(0.5-3.0)$ & $1.0(0-2.0)$ & 0.7 \\
\hline \multicolumn{6}{|l|}{ Causes of death } \\
\hline Malignant neoplasms (\%) & 28 & 31 & 28 & 0 & 0.2 \\
\hline
\end{tabular}




$\begin{array}{lccccc}\text { Heart diseases }(\%) & 17 & 17 & 11 & 11 & 0.1 \\ \text { Cerebrovascular diseases (\%) } & 17 & 11 & 3 & 11 & 0.4 \\ \text { Other diseases of circulatory } & 0 & 6 & 6 & 6 & 0.2 \\ \text { system }(\%) & 17 & 19 & 33 & 22 & 0.5 \\ \text { Infectious diseases (\%) } & 19 & 6 & 8 & 33 & 0.08 \\ \text { Other causes }(\%) & & & & 6\end{array}$

Values are mean \pm standard deviation or frequencies. Hypertension was defined as blood pressure $\geq 140 / 90$ mmHg or usage of anti-hypertensive agent. Diabetes was defined as $\mathrm{HbA}_{1 \mathrm{c}} \geq 6.0 \%$. Trends were tested by linear regression analysis for continuous variables or logistic regression analysis for categorical variables. eGFR, serum creatinine, serum urea nitrogen and triglycerides were described as median and interquartile range. Serum creatinine in $\mathrm{mg} / \mathrm{dL}$ may be converted to $\mu \mathrm{mol} / \mathrm{dL}$ by multiplying by 76.26 . Serum albumin may be converted to $\mathrm{g} / \mathrm{L}$ by multiplying by 10. Serum urea nitrogen, total cholesterol, HDL-C and triglycerides in $\mathrm{mg} / \mathrm{dL}$ may be converted to mmol/L by multiplying by 0.357, 0.02586, 0.02586 and 0.01129, respectively. eGFR, estimated glomerular filtration rate; HDL-C, high-density lipoprotein cholesterol. 
Table 2: Age- and sex-matched or multivariate-adjusted odds ratios for advanced coronary atherosclerotic lesion and calcified lesion according to kidney function.

\begin{tabular}{|c|c|c|c|c|c|c|c|c|c|c|c|c|c|c|c|c|}
\hline \multirow{2}{*}{$\begin{array}{c}\text { eGFR } \\
\text { categories }\end{array}$} & \multirow{2}{*}{$\begin{array}{c}\text { Number of } \\
\text { vessels } \\
\text { assessed }\end{array}$} & \multicolumn{7}{|c|}{ Age-and sex-adjusted ${ }^{\text {a) }}$} & \multicolumn{8}{|c|}{ Multivariate-adjusted ${ }^{\text {b) }}$} \\
\hline & & $\begin{array}{c}\text { Matched } \\
\text { OR }\end{array}$ & ( & & $5 \% \mathrm{CI}$ & ) & $\begin{array}{c}\mathrm{p} \\
\text { value }\end{array}$ & $\begin{array}{l}\mathrm{p} \text { for } \\
\text { trend }\end{array}$ & $\begin{array}{c}\text { Matched } \\
\text { OR }\end{array}$ & ( & & $5 \%$ & & ) & $\mathrm{p}$ value & $\begin{array}{l}\mathrm{p} \text { for } \\
\text { trend }\end{array}$ \\
\hline \multicolumn{17}{|c|}{ Advanced atherosclerosis (AHA type IV-VI) } \\
\hline$\geq 60$ & 107 & 1.00 & ( & $\operatorname{Ref}$ & erence & ) & & \multirow{4}{*}{0.006} & 1.00 & ( & \multicolumn{3}{|c|}{ Reference } & ) & & \multirow{4}{*}{0.01} \\
\hline $45-59$ & 108 & 1.51 & ( & 0.80 & -2.87 & ) & 0.20 & & 1.40 & ( & 0.76 & - & 2.55 & ) & 0.28 & \\
\hline $30-44$ & 107 & 2.22 & ( & 1.11 & -4.43 & ) & 0.02 & & 2.02 & ( & 0.99 & & 4.15 & ) & 0.05 & \\
\hline$<30$ & 53 & 2.38 & ( & 1.18 & - 4.81 & ) & 0.02 & & 3.02 & ( & 1.22 & - & 7.49 & ) & 0.02 & \\
\hline \multicolumn{17}{|l|}{ Calcified lesion } \\
\hline$\geq 60$ & 107 & 1.00 & ( & $\operatorname{Ref}$ & erence & ) & & & 1.00 & ( & $\operatorname{Re}$ & er & nce & ) & & \multirow{4}{*}{0.009} \\
\hline $45-59$ & 108 & 1.02 & ( & 0.50 & -2.08 & ) & 0.95 & \multirow{3}{*}{0.02} & 0.95 & ( & 0.46 & & 1.94 & ) & 0.89 & \\
\hline $30-44$ & 107 & 1.43 & ( & 0.71 & 2.89 & ) & 0.32 & & 1.43 & ( & 0.69 & - & 2.95 & ) & 0.34 & \\
\hline$<30$ & 53 & 2.75 & ( & 1.19 & 6.34 & ) & 0.02 & & 4.71 & ( & 1.78 & - & 12.50 & ) & 0.002 & \\
\hline
\end{tabular}

a) Odds ratios were adjusted for age and sex.

b) Odds ratios were adjusted for age, sex, hypertension, diabetes, total cholesterol, HDL-cholesterol, triglycerides, calcium-phosphorus product, hematocrit, smoking habits and alcohol intake.

eGFR, estimated glomerular filtration rate; OR, odds ratio; CI, confidence interval. 
Table 3: Association of the cardiovascular risk factors with the risk of the advanced coronary atherosclerotic lesion and calcified lesion in subjects with reduced kidney function

\begin{tabular}{|c|c|c|c|c|c|c|c|c|c|c|}
\hline Risk factor & & $\begin{array}{l}\mathrm{N} \text { of vessels } \\
\text { assessed }\end{array}$ & $\begin{array}{l}\text { Frequency } \\
\text { of lesion }\end{array}$ & OR & ( & \multicolumn{3}{|c|}{$95 \% \mathrm{CI}$} & ) & $\mathrm{p}$ \\
\hline \multicolumn{11}{|c|}{ Advanced atherosclerosis (AHA type IV-VI) } \\
\hline \multirow[t]{2}{*}{ Hypertension } & No & 71 & $38.0 \%$ & 1.00 & ( & \multicolumn{3}{|c|}{ reference } & ) & \\
\hline & Yes & 197 & $51.8 \%$ & 1.76 & ( & 0.93 & - & 3.35 & ) & 0.08 \\
\hline \multirow[t]{2}{*}{ Diabetes } & No & 212 & $43.4 \%$ & 1.00 & ( & \multicolumn{3}{|c|}{ reference } & ) & \\
\hline & Yes & 56 & $66.1 \%$ & 2.57 & ( & 1. 26 & - & 5.24 & ) & 0.01 \\
\hline \multirow[t]{2}{*}{ Dyslipidemia } & No & 143 & $42.7 \%$ & 1.00 & ( & \multicolumn{3}{|c|}{ reference } & ) & \\
\hline & Yes & 125 & $54.4 \%$ & 1.61 & ( & 0.91 & - & 2.86 & ) & 0.10 \\
\hline \multicolumn{11}{|c|}{ Calcified lesion } \\
\hline \multirow{2}{*}{ Hypertension } & No & 71 & $33.8 \%$ & 1.00 & ( & \multicolumn{3}{|c|}{ reference } & ) & \\
\hline & Yes & 197 & $48.7 \%$ & 1.88 & ( & 1.04 & - & 3.39 & ) & 0.04 \\
\hline \multirow[t]{2}{*}{ Diabetes } & No & 212 & $40.1 \%$ & 1.00 & ( & \multicolumn{3}{|c|}{ reference } & ) & \\
\hline & Yes & 56 & $62.5 \%$ & 2.91 & ( & 1.56 & - & 5.45 & ) & 0.0008 \\
\hline \multirow[t]{2}{*}{ Dyslipidemia } & No & 143 & $42.0 \%$ & 1.00 & ( & \multicolumn{3}{|c|}{ reference } & ) & \\
\hline & Yes & 125 & $48.0 \%$ & 1.25 & ( & 0.71 & - & 2.20 & ) & 0.45 \\
\hline
\end{tabular}

Hypertension was defined as blood pressure $\geq 140 / 90 \mathrm{mmHg}$ and/or usage of antihypertensive agent. Diabetes was defined as Hemoglobin $\mathrm{A}_{1 \mathrm{c}}$ $\geq 6.0 \%$. Dyslipidemia was defined as total cholesterol $\geq 220 \mathrm{mg} / \mathrm{dL}$, HDL-Cholesterol< $40 \mathrm{mg} / \mathrm{dL}$ and/or triglycerides $\geq 150 \mathrm{mg} / \mathrm{dL}$.

Odds ratios were adjusted for age and sex.

OR, odds ratio; CI, confidence interval. 
Figure 1

The residents deceased in the Hisayama town

(January 1988 - November 2005)

\section{1,162 cases}

The subjects underwent autopsy

\section{4 cases}

The subjects who had a health examination within 3 years before death.

\section{2 cases}

\section{The classification} based on eGFR levels

The subjects randomly selected from each eGFR category after matching for age and sex

\section{6 cases}


Figure 2

$60 \leq$ eGFR

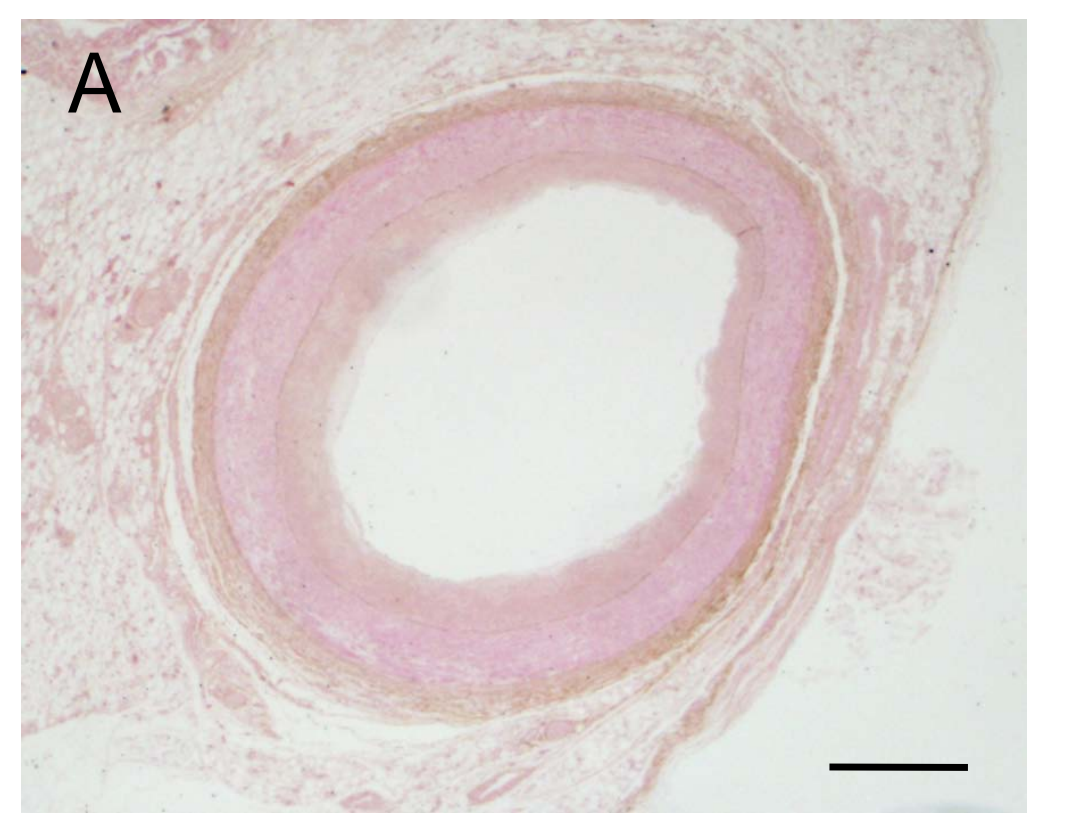

$30 \leq$ eGFR $<45$

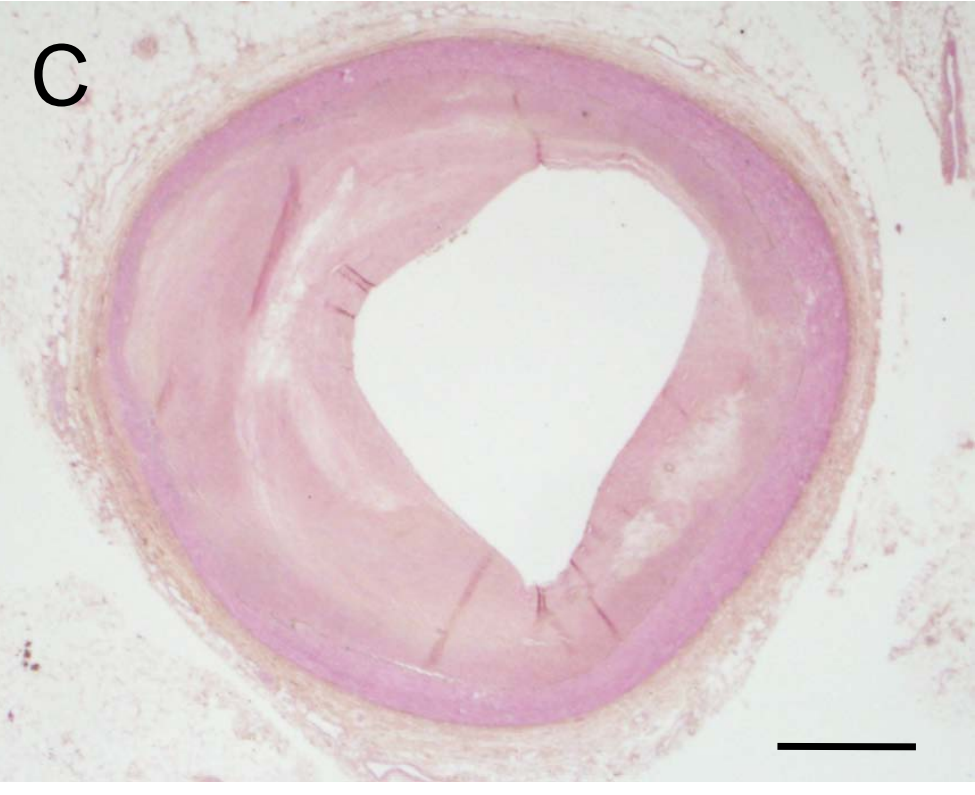

$45 \leq$ eGFR $<60$

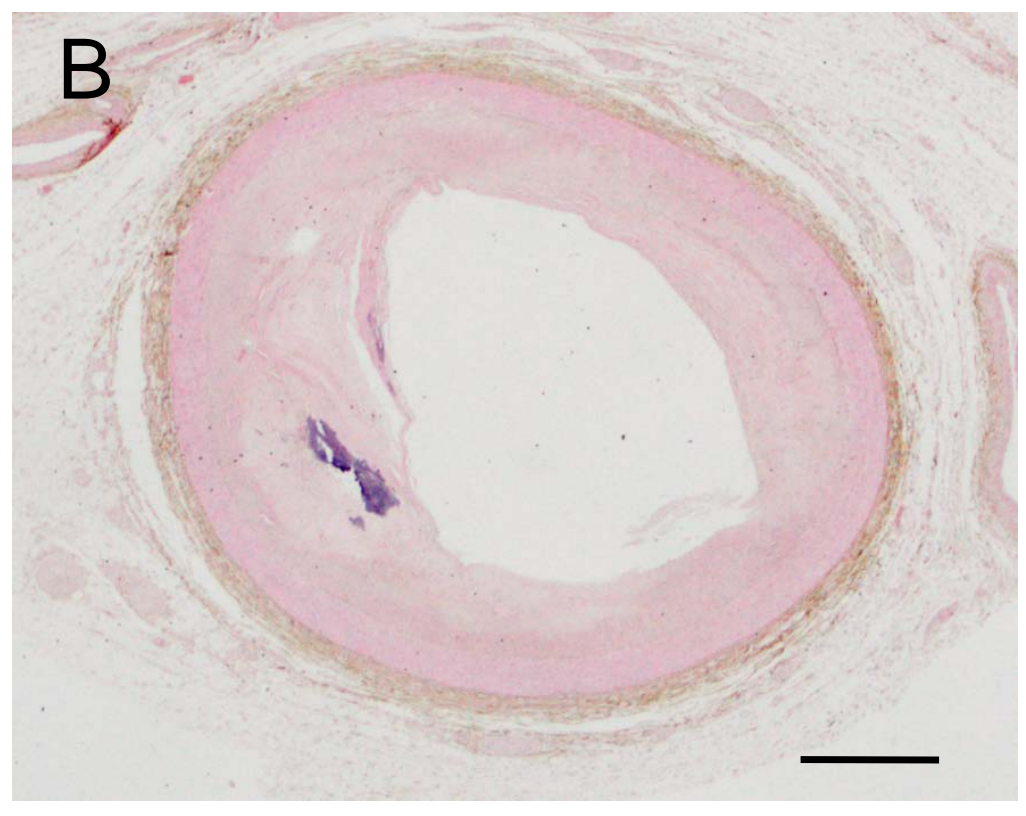

eGFR $<30$

D

0

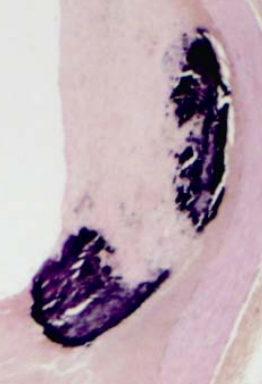




\section{Figure 3}

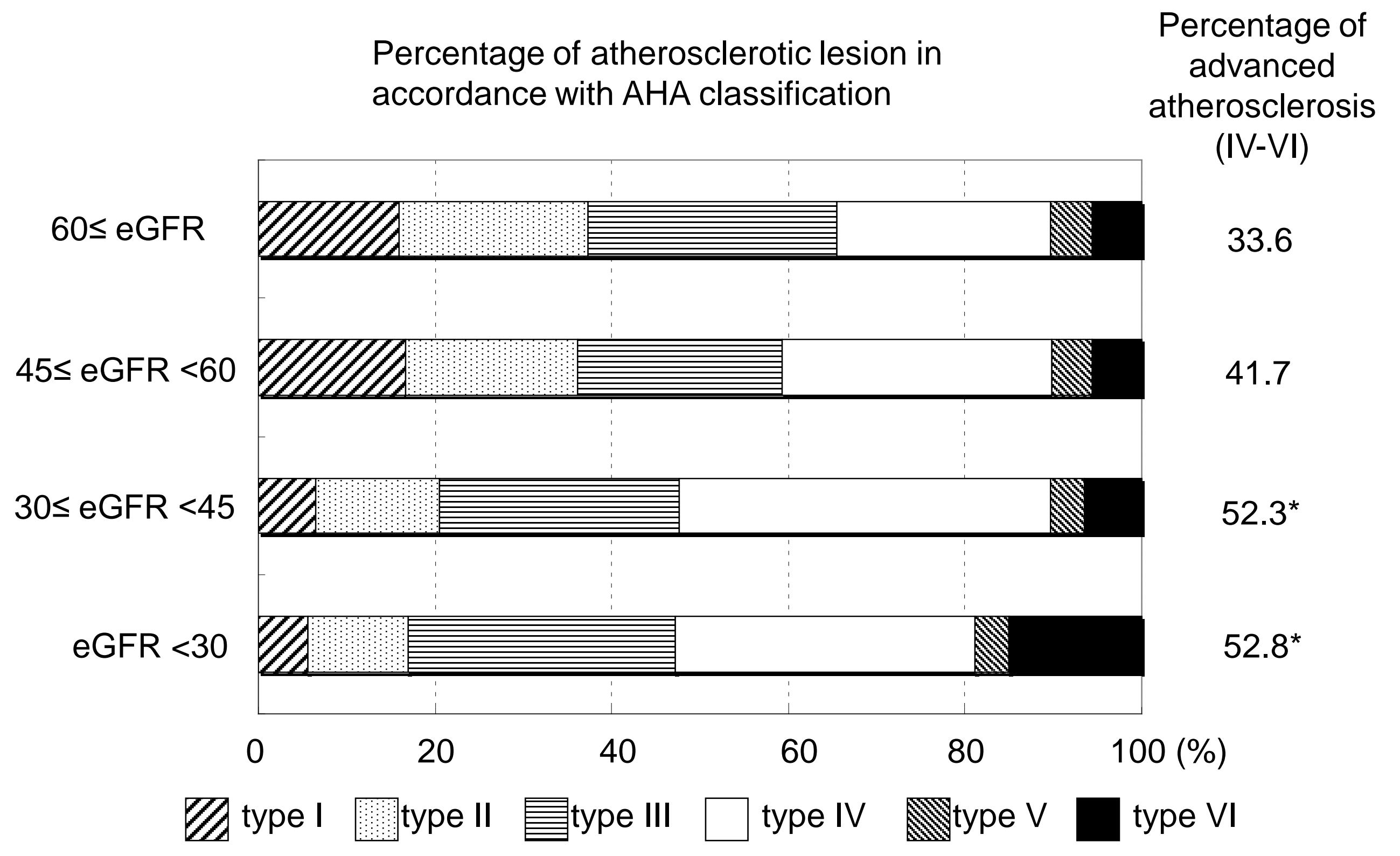


Figure 4

\section{AHA type VI}

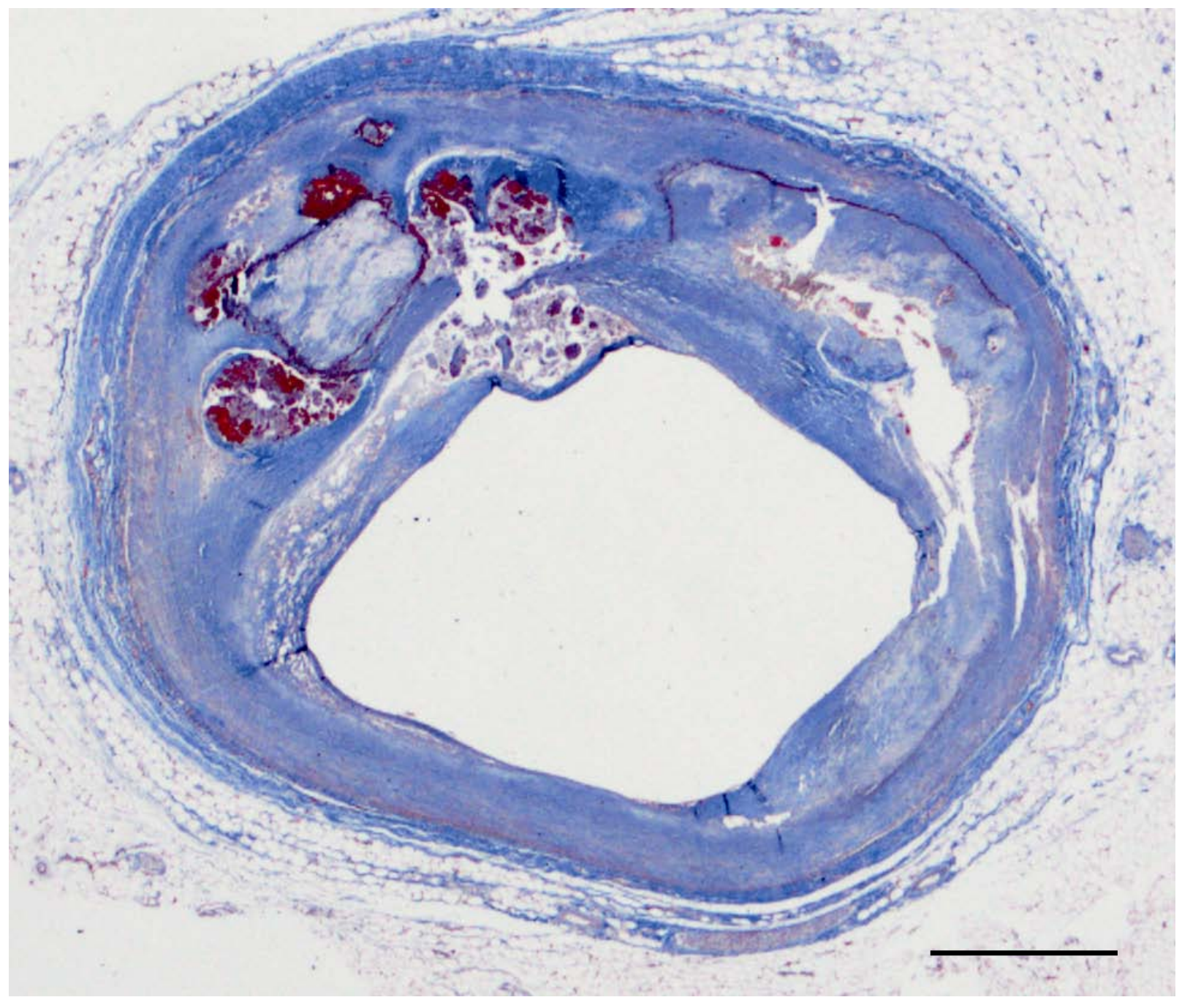

